\title{
O EFEITO OROGRÁFICO DA SERRA DO MAR E O POTENCIAL EROSIVO DAS CHUVAS NAS BACIAS HIDROGRÁFICAS DO RIBEIRA E LITORÂNEA - PARANÁ
}

\author{
TERASSI, Paulo Miguel de Bodas - pmbterassi@usp.br \\ Programa de Pós-Graduação em Geografia Física, Universidade de São \\ Paulo / USP \\ GALVANI, Emerson - egalvani@usp.br \\ Programa de Pós-Graduação em Geografia Física, Universidade de São \\ Paulo / USP
}

\begin{abstract}
RESUMO: O presente trabalho objetiva identificar o papel desempenhado pela orografia da Serra do Mar para a distribuição espacial da pluviosidade e das estimativas de erosividades das chuvas para as bacias hidrográficas do Ribeira e Litorânea, Paraná, nas escalas anual e mensal. Obtiveram-se os dados de pluviosidade de 32 postos pluviométricos do Instituto Águas do Paraná, da Agência Nacional de Águas (ANA) e da Companhia Paranaense de Energia (COPEL) para a série temporal de 1976 a 2015, com falhas inferiores a $5 \%$. Para estimar o potencial erosivo das chuvas, utilizou-se a equação proposta por Rufino, Biscaia e Merten (1993). Os resultados mostraram que a bacia hidrográfica Litorânea apresenta as maiores médias de pluviosidade e de erosividade das chuvas, sobretudo no período de janeiro a março, com a maior influência da maritimidade, da massa Tropical atlântica e ao efeito orográfico da Serra do Mar. A bacia hidrográfica do Ribeira, devido à obstrução da Serra do Mar, caracteriza-se pela sombra de chuvas e por menores totais pluviométricos.
\end{abstract}

Palavras- chaves: índice de erosividade, barlavento, sotavento, maritimidade.

THE OROGRAPHICAL EFFECT OF THE SERRA DO MAR AND THE RAINFALL EROSIVE POTENTIAL IN THE RIBEIRA AND COASTAL WATERSHEDS - PARANÁ

ABSTRACT: This paper aims to identify the orographic effect and their influence to the rainfall spatial distribution and rainfall erosivity estimates for the Ribeira and Coastal watersheds in the annual and monthly scale. Were obtained the rainfall data from 32 rain gauges stations provided by Paraná Water Institute, the National Water Agency (NWA) and Energy Company of Paraná (ECP) for the historical data serie from 1976 to 2015.The data failure signified less than $5 \%$. To estimate the erosive potential of rainfall was used the equation proposed by Rufino, Biscaia and Merten (1993). The results showed that the Coastal watershed has the highest average of rainfall and rainfall erosivity, especially in the period from January to March, with the greatest influence of maritimity and atlantic Tropical mass and the orographic effect of the Serra do Mar. The Ribeira watershed, due to the Serra do Mar obstruction, is characterized by the rain shadows and the lowest rainfall totals.

Keywords: erosivity index, windward side, leeward side, oceanic influence.

\section{INTRODUÇÃO}

A pluviosidade é um dos atributos climáticos de maior importância por corresponder ao fator preponderante na quantificação da necessidade de irrigação de culturas e do abastecimento doméstico e industrial (ARAI et al., 2010). Na interação com os demais componentes da dinâmica ambiental, devido à abundância e aos elevados totais anuais, a pluviosidade se destaca em países tropicais pela capacidade de ocasionar a erosividade (SILVA, 2004; HOYOS et al., 2005; TRINDADE et al., 2016; PANAGOS et al., 2017). 
Enquanto que a erodibilidade consiste na resistência e suscetibilidade do solo à erosão hídrica, devido à permeabilidade do solo à água, da capacidade de armazenamento de água e do tipo textural de seus constituintes (SILVA et al., 2009), a erosividade corresponde às forças ativas das chuvas e, segundo Oliveira et al.(2012), é conceituada como a capacidade da chuva em causar erosão do solo. A erosividade está diretamente relacionada com a quantidade de energia cinética e intensidade da chuva gerada e impactada em determinada porção de solo.

A determinação do potencial da erosividade das chuvas corresponde a uma informação essencial para a determinação do risco de áreas e períodos mais susceptíveis a erosão (MONTEBELLER et al., 2007; OLIVEIRA et al., 2012) e, desta forma, para o manejo de bacias hidrográficas por permitir a determinação de práticas adequadas de conservação do solo (ZHANG et al., 2005; MA et al., 2012; SOUZA; GASPARETTO, 2012).

Carvalho (2014) destaca que a bacia hidrográfica tem sido utilizada como unidade de estudo para a compreensão da dinâmica e dos problemas ambientais. A adoção da bacia hidrográfica propicia a possibilidade de uma análise integrada, uma vez que sua estrutura, funcionamento e organização a definem como um recorte espacial sistêmico, pois corresponde onde se realizam os balanços de entrada e saída de água pelo exutório (PORTO; PORTO, 2008; RODRIGUES, 2010; LUZ; RODRIGUES, 2015).

Os estudos acerca do desempenho orográfico para a distribuição das chuvas em bacias hidrográficas é de alta relevância, pois a orografia é um importante fator atuante na dinâmica dos atributos constituintes do clima, de forma a intensificar ou reduzir os totais de pluviosidade, conforme a posição a barlavento ou a sotavento (CANDIDO; NUNES, 2008). Como exemplo, Ribeiro (1987) descreve a significância do efeito orográfico no controle da distribuição espacial da pluviosidade na bacia hidrográfica do rio Pirapó (PR), indicando que ocorre uma redução de aproximadamente de $35 \%$ da média de chuvas na foz em relação à nascente.

Andrade e Nery (2003) discorrem que a maior variabilidade espacial e os maiores totais pluviométricos no setor centro-sul da bacia hidrográfica do rio Ivaí (PR) estão associados, preponderantemente, a maior variação e elevações do relevo. Chierice e Landim (2014) observaram que a bacia hidrográfica do rio Mogi Guaçu (SP) apresenta seus maiores totais pluviométricos nos setores de maiores elevações, com uma diminuição significativa em direção à foz do curso principal do rio supracitado. Fontão e Zavattini (2014) compartimentaram a bacia hidrográfica do Pardo, localizada nos estados de São Paulo e Minas Gerais, em seis unidades conforme a características do relevo como critério inicial para analisar a distribuição espacial da pluviosidade.

A área selecionada para o presente estudo corresponde às bacias hidrográficas do Ribeira e Litorânea, situadas no setor leste do estado do Paraná, entre os meridianos $48^{\circ} \mathrm{W}$ e $50^{\circ} \mathrm{W}$ e os paralelos $24.4{ }^{\circ} \mathrm{S}$ e $26^{\circ} \mathrm{S}$, e apresentam, respectivamente, a abrangência de $9736 \mathrm{~km}^{2}$ e $5630 \mathrm{~km}^{2}$ (ITCG, 2015) (Figura 1). Embora a bacia hidrográfica do rio Ribeira abranja também o estado de São Paulo, este trabalho restringe-se a estudar o setor paranaense desta bacia hidrográfica. 


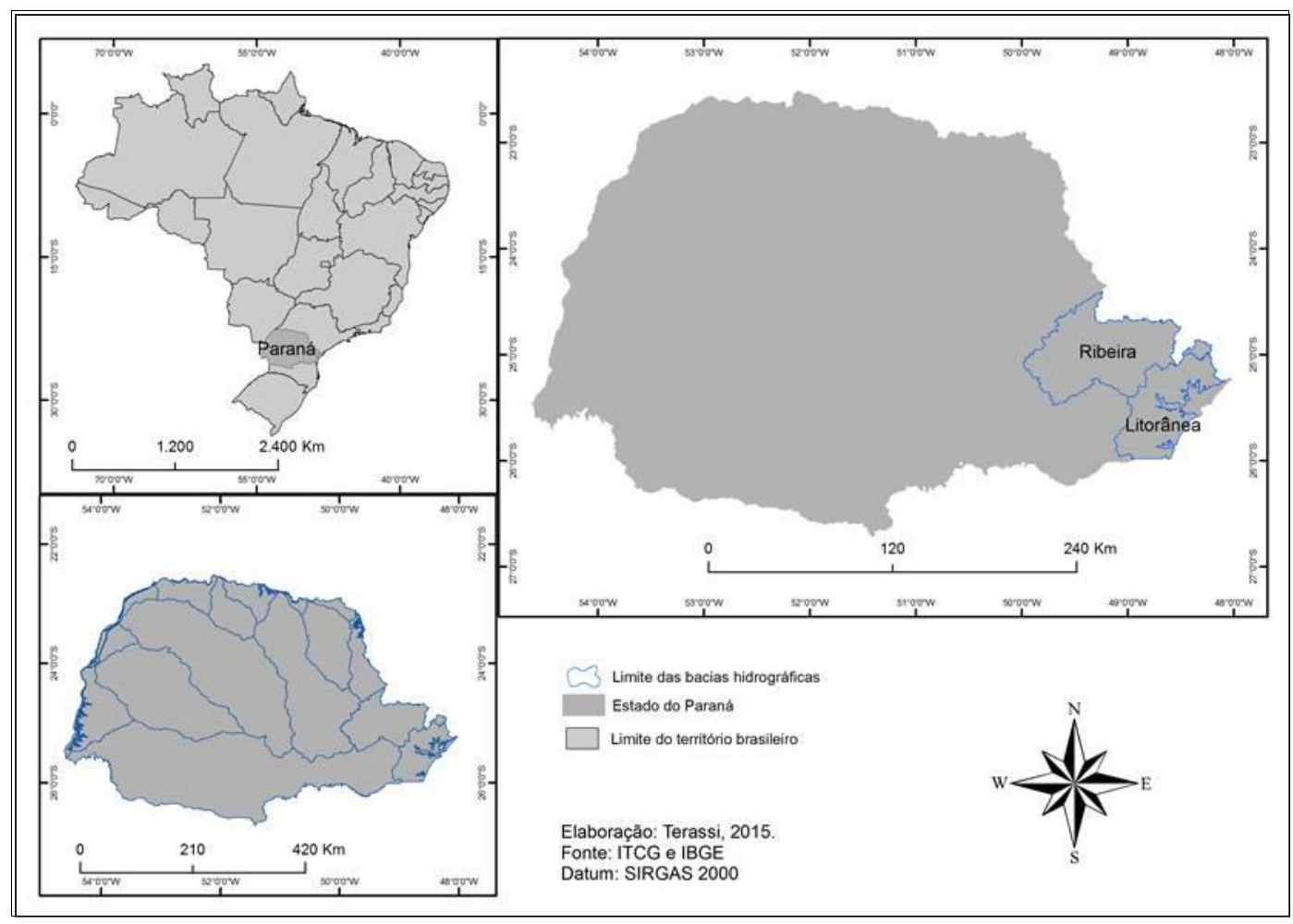

Figura 1 - Localização das bacias hidrográficas do Ribeira e Litorânea - Paraná.

Um dos principais critérios para a escolha desta área de estudo está na influência da orografia e da maritimidade para a ocorrência de maiores totais de pluviosidade para a vertente oceânica, na qual se situa a bacia Litorânea, e, devido ao obstáculo da Serra do Mar (Figura 2), a significativa redução dos totais pluviométricos em direção ao interior do continente, na bacia hidrográfica do Ribeira. Segundo a classificação climática de Köppen (1948) realizada por Cavaglione et al. (2010), Álvares et al. (2013) e Aparecido et al. (2016), a área de estudo caracteriza-se pelo clima subtropical dos tipos Cfa e Cfb e, no entanto, devido a influência de atributos climáticos como a orografia e a maritimidade, as bacias hidrográficas diferencem-se significativamente nos totais médios anuais de pluviosidade, conforme indicam Fritzsons et al. (2011) para estes mesmos setores do estado do Paraná.

A suposição citada acima parte de diversos trabalhos que destacam a influência orográfica da Serra do Mar na distribuição espacial da pluviosidade em diferentes nos estados de São Paulo (SANT'ANNA NETO, 1994; PELEGATTI; GALVANI, 2010), Rio de Janeiro (BRITO et al., 2016) e Paraná (VANHONI; MENDONÇA, 2008; SILVA et al., 2012). Dentre os mais recentes estudos, Pellegatti e Galvani (2010) evidenciaram que a Serra do Mar, ao longo do litoral paulista, em sua vertente a barlavento, apresenta totais pluviométricos que estão entre os mais elevados do Brasil, superiores a $3.000 \mathrm{~mm}$, ao passo que a vertente situada a sotavento caracteriza-se por uma pluviosidade média anual de aproximadamente $1.500 \mathrm{~mm}$, demostrando a importância das elevações e da orientação do relevo frente à atuação dos sistemas atmosféricos e o efeito da maritimidade. 
Por sua vez, Milanesi e Galvani (2011) descrevem que o efeito orográfico corresponde a qualquer controle que o relevo exerce sobre os atributos do clima, sendo que a interação entre os dois componentes podem gerar perturbações naturais na dinâmica atmosférica em conformidade a morfologia do relevo. Estes mesmo autores complementam que as resultantes desse processo interativo entre a atmosfera e a crosta terrestre são os gradientes de temperatura e pressão, a obstrução e bifurcação de ventos e a geração de brisas e nuvens, além da chuva orográfica e a sombra da chuva.

Conforme Koga-Vicente e Nunes (2011), a maritimidade é um dos fatores preponderante para a ocorrência de chuvas extremas em um período de 24 horas em regiões litorâneas, condições que resultam em calamidades públicas, tanto avarias materiais quanto humanas. Toneti et al. (2013) relatam que o período de janeiro a março é o mais vulnerável a alagamentos em Paranaguá, no Litoral do Paraná, devido ao elevado aumento da pluviosidade, resultante do que Vanhoni e Mendonça (2008) descreveram como a atuação mais incisiva da massa Tropical Atlântica.

Considerando a literatura consultada, o presente trabalho objetiva identificar o papel desempenhado pela orografia da Serra do Mar para a distribuição espacial da pluviosidade e das estimativas de erosividades das chuvas para as bacias hidrográficas do Ribeira e Litorânea nas escalas anual e mensal.

\section{MATERIAIS E MÉTODOS}

Obtiveram-se os dados de pluviosidade de 32 postos pluviométricos junto ao Instituto Águas do Paraná, da Agência Nacional de Águas (ANA) e da Companhia Paranaense de Energia (COPEL), que compreendem a série histórica de 1976 a 2015 (Figura 2 - Quadro 1), selecionados conforme o menor número de falhas, todos inferiores a $5 \%$ do segmento temporal. 0 posto pluviométrico de Campo Largo (Itaqui), situado na bacia hidrográfica do Iguaçu, foi utilizado para o preenchimento de falhas dos postos pluviométricos mais próximos, conforme preconizado por Bertoni e Tucci (1997).

Os dados faltantes dos postos pluviométricos foram preenchidos seguindo o método de ponderação regional apresentado por Villela e Mattos (1975), que segundo Oliveira et al. (2010), corresponde a um dos métodos mais adequados para o preenchimento de falhas de dados pluviométricos. Esse método tem como base o registro pluviométrico de três postos localizados o mais próximo possível do posto em que se verifica a falta de dados, com características pluviométricas (distribuição mensal e os totais anuais) e altitudes semelhantes. Os registros faltantes de pluviosidade foram estimados pela média ponderada do registro das três estações vizinhas, onde os pesos são as razões entre as precipitações normais anuais.

Os gráficos de pluviosidade e erosividade mensal foram elaborados a partir da utilização da planilha eletrônica Microsoft Office Excel 2007. Para a realização do perfil esquemático da pluviosidade e da erosividade das chuvas, os postos pluviométricos foram ordenados da menor para a maior hipsometria na bacia hidrográfica litorânea e, inversamente, para a bacia hidrográfica do Ribeira, com a finalidade de demonstrar o controle orográfico da Serra do Mar para a distribuição espacial da pluviosidade, de acordo com as características do 
relevo mostrado pela figura 2, seguindo o mesmo modelo de Correa (2013) e Correa e Galvani (2016).

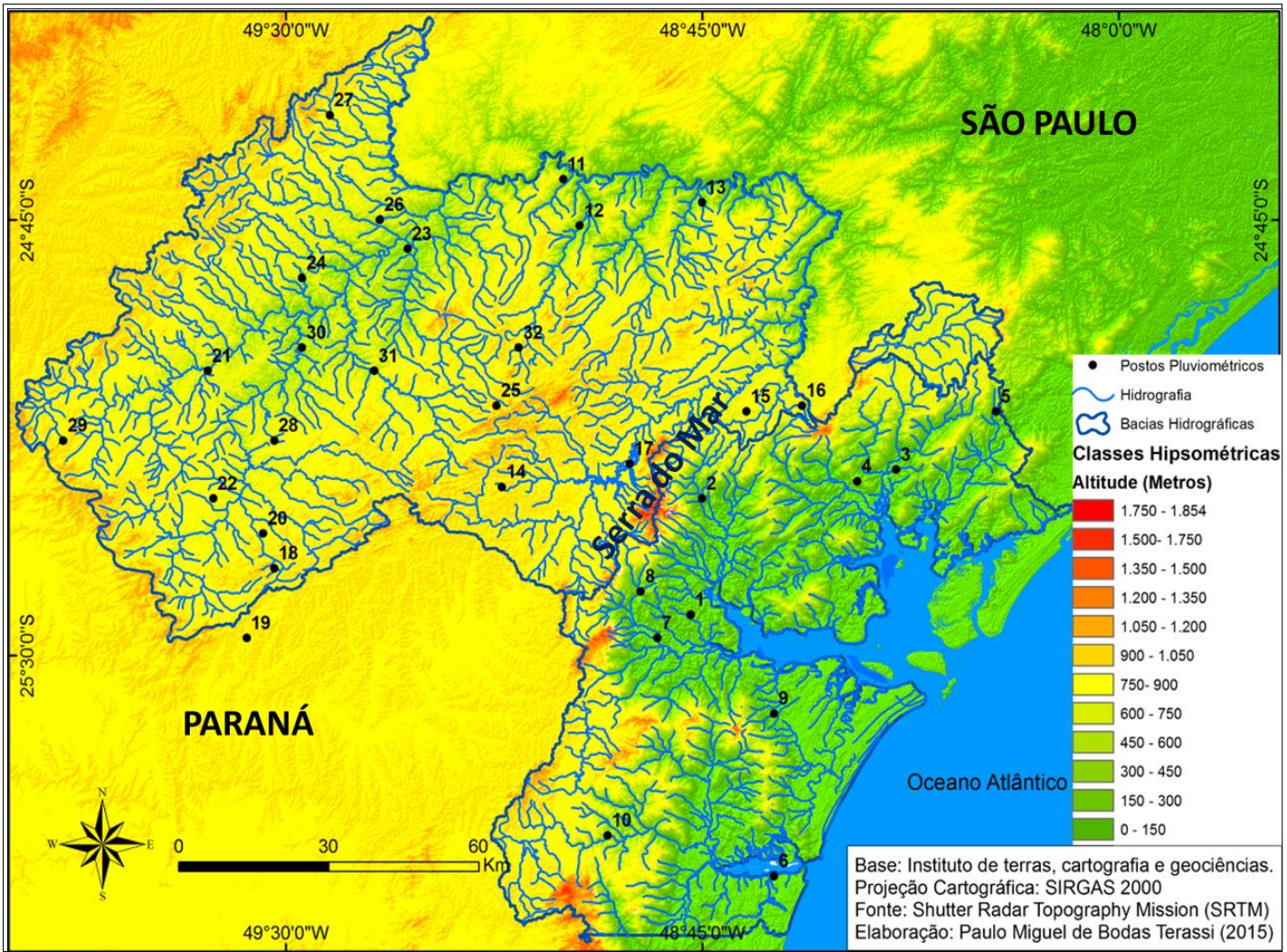

Figura 2 - Localização geográfica dos postos pluviométricos localizados nas bacias hidrográficas do Ribeira e Litorânea - Paraná.

Quadro 1 - Localização geográfica dos postos pluviométricos nas bacias hidrográficas (BH) do Ribeira e Litorânea - Paraná.

\begin{tabular}{|c|c|c|c|c|c|c|}
\hline № & $\begin{array}{c}\text { Código } \\
\text { ANEEL }\end{array}$ & Postos Pluviométricos & $\begin{array}{c}\text { Alt. } \\
(\mathrm{m})\end{array}$ & $\begin{array}{c}\text { Lat. } \\
(\mathrm{oS})\end{array}$ & $\begin{array}{c}\text { Long. } \\
(\mathrm{o} \text { ) })\end{array}$ & BH \\
\hline 1 & 2548068 & Antonina & 74 & 25,43 & 48,77 & Litorânea \\
\hline 2 & 2548003 & Antonina & 80 & 25,23 & 48,75 & Litorânea \\
\hline 3 & 2548043 & Guaraqueçaba & 16 & 25,18 & 48,40 & Litorânea \\
\hline 4 & 2548044 & Guaraqueçaba & 73 & 25,20 & 48,47 & Litorânea \\
\hline 5 & 2548042 & Guaraqueçaba & 9 & 25,08 & 48,22 & Litorânea \\
\hline 6 & 2548053 & Guaratuba & 20 & 25,88 & 48,62 & Litorânea \\
\hline 7 & 2548000 & Morretes & 8 & 25,47 & 48,83 & Litorânea \\
\hline 8 & 2548047 & Morretes & 88 & 25,39 & 48,86 & Litorânea \\
\hline 9 & 2548049 & Paranaguá & 32 & 25,60 & 48,62 & Litorânea \\
\hline 10 & 2548052 & São José dos Pinhais & 237 & 25,81 & 48,92 & Litorânea \\
\hline 11 & 2449000 & Adrianópolis & 180 & 24,68 & 49,00 & Ribeira \\
\hline 12 & 2448037 & Adrianópolis & 227 & 24,76 & 48,97 & Ribeira \\
\hline 13 & 2448035 & Adrianópolis & 270 & 24,72 & 48,75 & Ribeira \\
\hline 14 & 2549051 & Bocaiúva do Sul & 969 & 25,21 & 49,11 & Ribeira \\
\hline
\end{tabular}




\begin{tabular}{|l|l|c|c|c|c|c|}
\hline 15 & 2548040 & Campina G. do Sul & 670 & 25,08 & 48,67 & Ribeira \\
\hline 16 & 2548036 & Campina G. do Sul & 642 & 25,07 & 48,57 & Ribeira \\
\hline 17 & 2548001 & Campina G. do Sul & 750 & 25,17 & 48,88 & Ribeira \\
\hline 18 & 2549045 & Campo Largo & 890 & 25,35 & 49,52 & Ribeira \\
\hline 19 & 2549019 & Campo Largo & 901 & 25,47 & 49,57 & Iguaçu \\
\hline 20 & 2549048 & Campo Largo & 781 & 25,29 & 49,54 & Ribeira \\
\hline 21 & 2549056 & Campo Largo & 517 & 25,01 & 49,64 & Ribeira \\
\hline 22 & 2549047 & Campo Largo & 800 & 25,23 & 49,63 & Ribeira \\
\hline 23 & 2449006 & Cerro Azul & 270 & 24,80 & 49,28 & Ribeira \\
\hline 24 & 2449013 & Cerro Azul & 480 & 24,85 & 49,47 & Ribeira \\
\hline 25 & 2549054 & Cerro Azul & 938 & 25,07 & 49,12 & Ribeira \\
\hline 26 & 2449007 & Doutor Ulysses & 400 & 24,75 & 49,33 & Ribeira \\
\hline 27 & 2449021 & Doutor Ulysses & 818 & 24,57 & 49,42 & Ribeira \\
\hline 28 & 2549053 & Itaperuçu & 750 & 25,13 & 49,52 & Ribeira \\
\hline 29 & 2549052 & Ponta Grossa & 1012 & 25,13 & 49,90 & Ribeira \\
\hline 30 & 2449063 & Rio Branco do Sul & 150 & 24,97 & 49,47 & Ribeira \\
\hline 31 & 2449020 & Rio Branco do Sul & 480 & 25,01 & 49,34 & Ribeira \\
\hline 32 & 2449024 & Tunas do Paraná & 880 & 24,97 & 49,08 & Ribeira \\
\hline
\end{tabular}

O índice de erosividade da chuva foi calculado com a utilização dos dados de precipitação média mensal e anual dos 32 postos pluviométricos. Para estabelecer os valores do índice erosividade (EIm) foi utilizada a equação do tipo $\mathrm{Y}=\mathrm{a}+\mathrm{bx}$, onde: $\mathrm{Y}=$ índice de erosão (MJ.mm.ha $\left.\mathrm{h}^{-1} \cdot \mathrm{h}^{-1} \cdot \mathrm{ano}^{-1}\right) ; \mathrm{a}$ e $\mathrm{b}=$ coeficientes linear e angular, e $x=p 2 / P$ (pluviosidade mensal ao quadrado dividida pela pluviosidade anual), apresentada por Rufino, Biscaia e Merten (1993) para o estado do Paraná. Os valores determinados para a área de estudo encontram-se predominantemente na região isoerosiva $8(Y=3,39+4,15 x)$. Essas atribuições deram parâmetro para a equação 1.

$$
\mathrm{EI}_{\mathrm{m}}=3,39+4,15\left(\frac{\mathrm{p}^{2}}{\mathrm{P}}\right)^{9,80665}
$$

Onde: EIm - Índice mensal de erosividade da chuva em MJ (mm.ha-1.h. $\left.\mathrm{h}^{-1} \cdot \mathrm{mês}^{-1}\right)$; a - coeficiente linear; b - coeficiente angular; $\mathrm{p}$ - Precipitação média mensal em milímetros; P - Precipitação média anual em milímetros; 9,80665 - Conversão kgf (quilograma força) para MJ (Megajoule).

Para a elaboração das cartas de distribuição da precipitação pluviométrica e da erosividade das chuvas foi utilizado o aplicativo Surfer versão 11.0. A interpolação dos dados foi feita através do método de Kriging, por permitir uma representação mais adequada da continuidade dos fenômenos geográficos e, mais especificamente, do fenômeno pluvial e a erosividade, conforme apontado por Carvalho e Assad (2005) e Silva et al. (2010).

\section{RESULTADOS E DISCUSSÕES}

O mapa das figuras 3 e 4 demonstram a elevada variação espacial da pluviosidade e da erosividade na área de estudo. A bacia hidrográfica Litorânea apresenta pluviosidade média anual de $2.385,7 \mathrm{~mm}$ e erosividade média equivalente a $11.146 \mathrm{MJ} . \mathrm{mm} \cdot \mathrm{ha}^{-1} \cdot \mathrm{h}^{-1} \cdot \mathrm{ano}^{-1}$, superiores aos $10.000 \mathrm{MJ} . \mathrm{mm} \cdot \mathrm{ha}^{-}$ 
1. $\mathrm{h}^{-1}$.ano-1 indicados por Waltrick et al. (2015). Observa-se os maiores valores para os setores nordeste e central, superiores a $2.700 \mathrm{~mm}$ e a 13.000 MJ.mm.ha-1 $\mathrm{h}^{-1} \cdot \mathrm{ano}^{-1}$, enquanto o setor oeste obteve as menores médias anuais, inferiores a $2.100 \mathrm{~mm}$ e a $9.500 \mathrm{MJ} \cdot \mathrm{mm} \cdot \mathrm{ha}^{-1} \cdot \mathrm{h}^{-1} \cdot \mathrm{ano}^{-1}$.

A bacia hidrográfica do Ribeira obteve pluviosidade média anual de $1.495,0 \mathrm{~mm}$ e erosividade média anual de 7.072,7 MJ.mm.ha-1. $\mathrm{h}^{-1}$.ano-1, com valores superiores a $1.800 \mathrm{~mm}$ e a $9.000 \mathrm{MJ} . \mathrm{mm} \cdot \mathrm{ha}^{-1} \cdot \mathrm{h}^{-1}$.ano-1 para os setores mais elevados nas proximidades da Serra do Mar, ao passo que nos setores de menores elevações na região do Vale do Ribeira, a pluviosidade é inferior a $1.300 \mathrm{~mm}$ e a erosividade média inferior a $7.000 \mathrm{MJ} . \mathrm{mm} \cdot \mathrm{ha}^{-1} \cdot \mathrm{h}^{-1}$.ano-1, com os intervalos de erosividade alinhados aos obtidos por Waltrick et al. (2015).

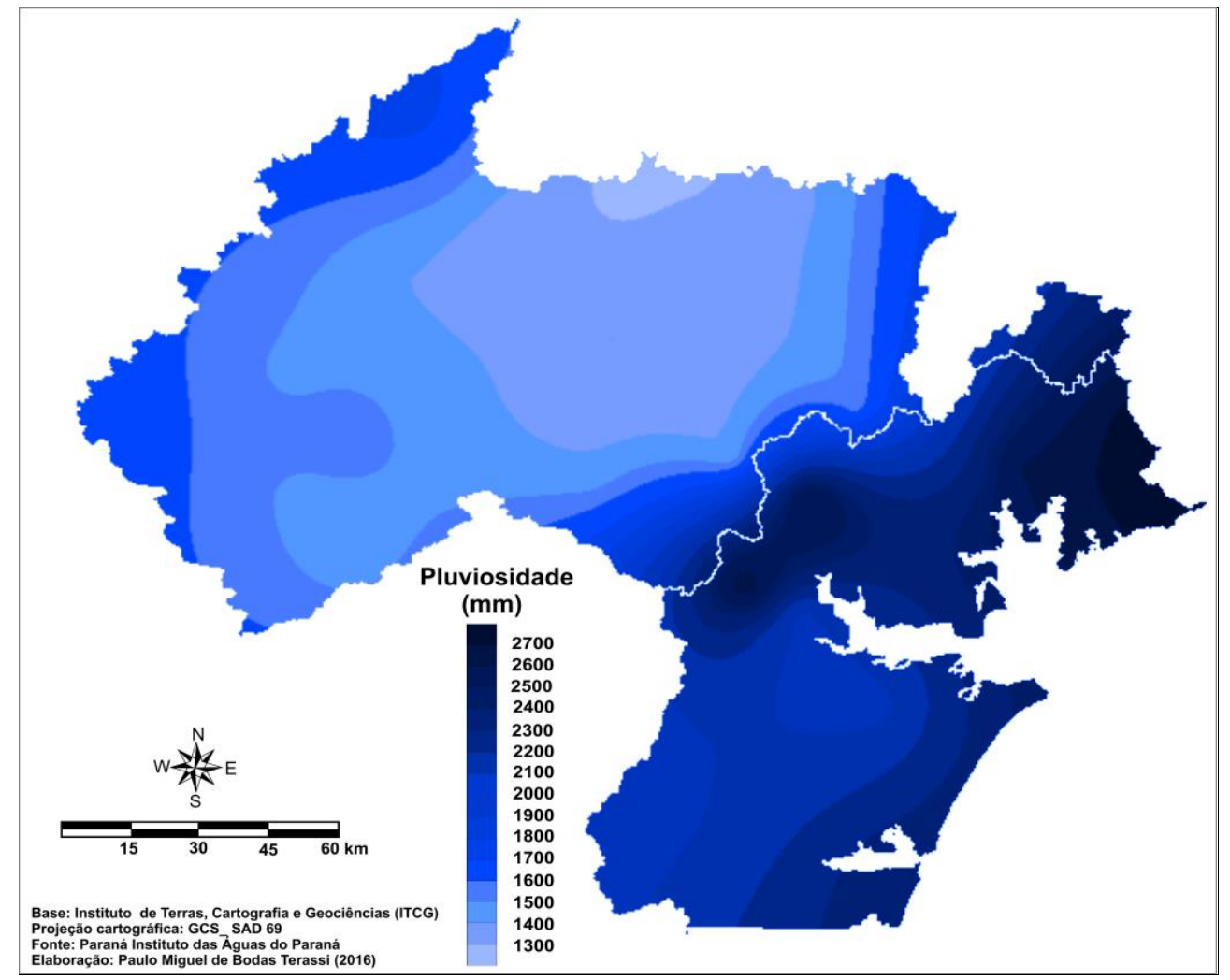

Figura 3 - Distribuição espacial da precipitação média anual ( $\mathrm{mm}$ ) para as bacias hidrográficas do rio Ribeira e Litorânea - Paraná.

O perfil esquemático da pluviosidade e da erosividade média anual permite avaliar a relação com os fatores orografia e maritimidade nas bacias hidrográficas do Ribeira e Litorânea (Figura 5). Os resultados mostraram que a vertente oceânica da Serra do Mar, na qual está situada a bacia hidrográfica Litorânea, apresenta uma pluviosidade média anual que varia entre 2.070 e $2.725 \mathrm{~mm}$ e uma erosividade média anual entre 9.720 e $12.970 \mathrm{MJ} . \mathrm{mm} \cdot \mathrm{ha}^{-1} \cdot \mathrm{h}^{-}$ ${ }^{1}$. ano ${ }^{-1}$, destacando o papel desempenhado pela maritimidade para a ocorrência de maiores totais de pluviosidade. Por sua vez, a bacia hidrográfica do Ribeira caracteriza-se por uma pluviosidade média anual entre 1.215 e $1.880 \mathrm{~mm}$ e uma erosividade média anual entre 5.980 e $9.100 \mathrm{MJ} \cdot \mathrm{mm} \cdot \mathrm{ha}^{-1} \cdot \mathrm{h}^{-1} \cdot \mathrm{ano}^{-1}$. 


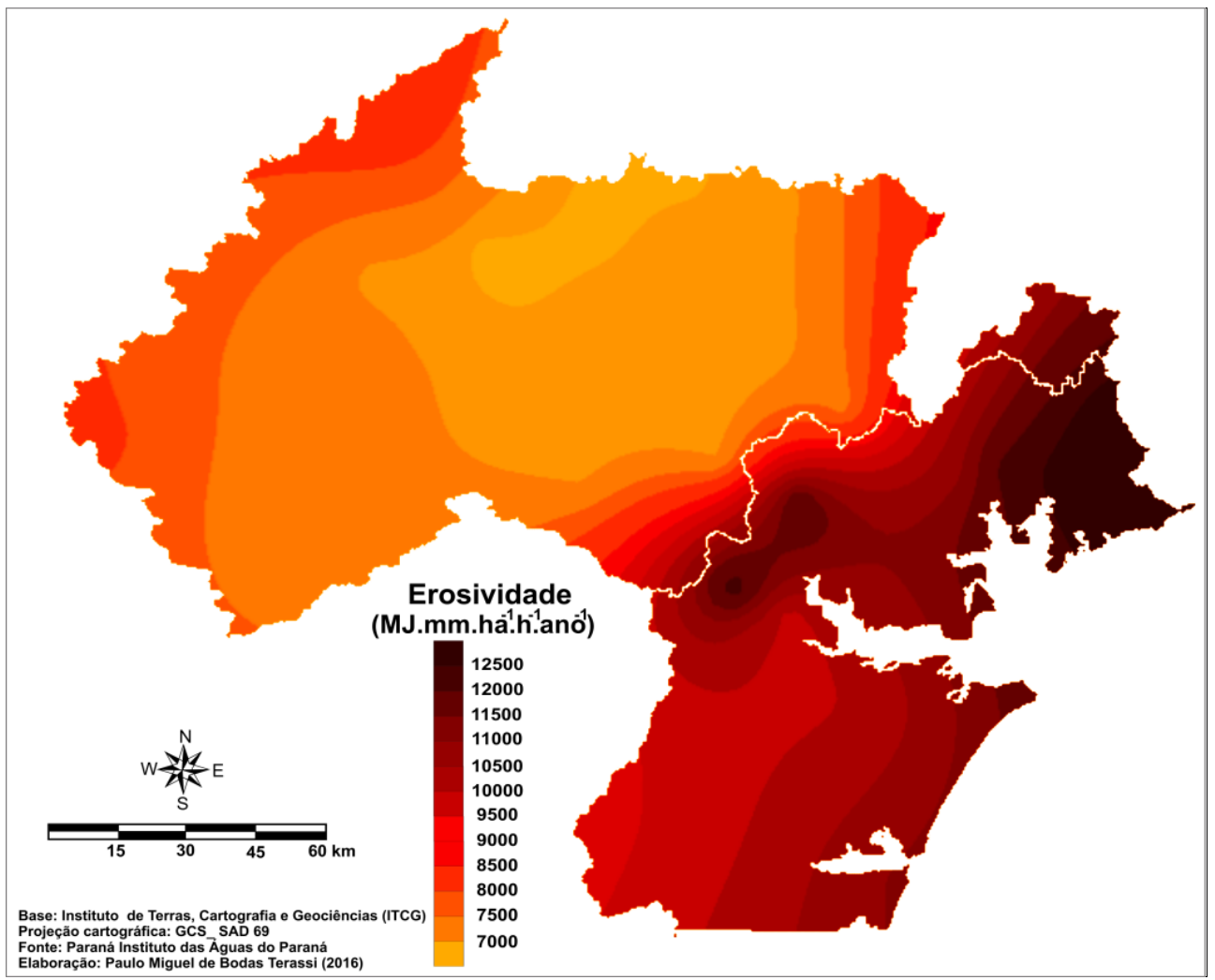

Figura 4 - Distribuição espacial da erosividade média anual (MJ.mm.ha-1.h-1. ano-1) para as bacias hidrográficas do rio Ribeira e Litorânea - Paraná.

Estes resultados estão aproximados ao que Sant'Anna Neto (1995) obteve para o estado de São Paulo, uma vez que a erosividade média anual obtida para a encosta litorânea foi superior a $12.000 \mathrm{MJ} \cdot \mathrm{mm} \cdot \mathrm{ha}^{-1} \cdot \mathrm{h}^{-1}$.ano-1, ao passo que o Vale do Paraíba e do Ribeira, situados a sotavento da brisa marítima e continente adentro, mostraram valores entre 5.000 a 6.500 MJ.mm.ha-1.h-1.ano-1. Assim como na zona Costeira do estado de São Paulo (SANT'ANNA NETO, 1994), o efeito da Maritimidade, aliado a atuação intensificada dos sistemas atmosféricos intertropicais e a predominância dos sistemas frontais na geração de chuvas, respondem pelos elevados totais pluviométricos na Planície Costeira paranaense, como também observado por Maack (2012).

Conforme Grimm (2009), no Litoral do Paraná, há significativa contribuição do efeito orográfico para a ocorrência de maiores totais pluviométricos, uma vez que os ventos em superfície divergem da Alta Subtropical do Atlântico Sul e sopram perpendicularmente à costa, e são forçados a ascender pela presença da Serra do Mar, próxima ao Litoral. Fritzsons et al. (2011) descrevem que o Litoral do Paraná apresenta a maior pluviosidade do território paranaense devido ao fator orográfico da Serra do Mar, brisa marítima e o contraste térmico entre a terra e as águas interiores.

Inversamente, a bacia hidrográfica do Ribeira caracteriza-se pela redução dos totais de pluviosidade e do potencial erosivo das chuvas justamente pela barreira orográfica da Serra do Mar, que forma uma sombra de chuvas, que 
reduz a pluviosidade em 37,3\% (Figura 5). Fritzsons et al. (2011) destacam que a localização geográfica em relação à Serra do Mar atribui a esta bacia hidrográfica uma condição atípica da distribuição pluviométrica mensal para esta latitude, uma vez que o setor Meridional do território paranaense predomina homogeneidade do regime pluviométrico devido às características próprias à dinâmica atmosférica do clima subtropical da região sul do Brasil e, entretanto, os resultados demonstraram que a bacia do Ribeira apresenta uma significativa redução pluviométrica para os meses de outono e inverno, condição própria ao clima Tropical do Brasil Central, conforme indicado por Nimer (1989) e Nery, Martins e Sant'Anna Neto (2000).

Conforme indicado pelas figuras 3, 4 e 5, e em concordância ao obtido em outras bacias hidrográficas por Andrade e Nery (2003) e Candido e Nunes (2008), é possível notar que os setores com maiores variações do relevo, sobretudo nas proximidades da Serra do Mar, observam-se as maiores variações dos totais de pluviosidade e das estimativas de erosividade. De modo inverso, os setores com as menores variações das altitudes mostraram as menores variações espaciais, especialmente nas menores elevações do setor norte da bacia hidrográfica do Ribeira, sendo que a morfologia do terreno exerce pouca influência para intensificação das chuvas nesta região.

Destaca-se também que na bacia hidrográfica Litorânea, com a diversidade de mecanismos para a geração de chuvas, dada à influência marítimica, verifica-se uma maior variação espacial dos totais pluviométricos anuais. Contrariamente, devido ao impedimento orográfico da Serra de Mar, a bacia hidrográfica do Ribeira restringe-se mais estreitamente aos mecanismos de mesoescala e macroescala para a formação de chuvas.

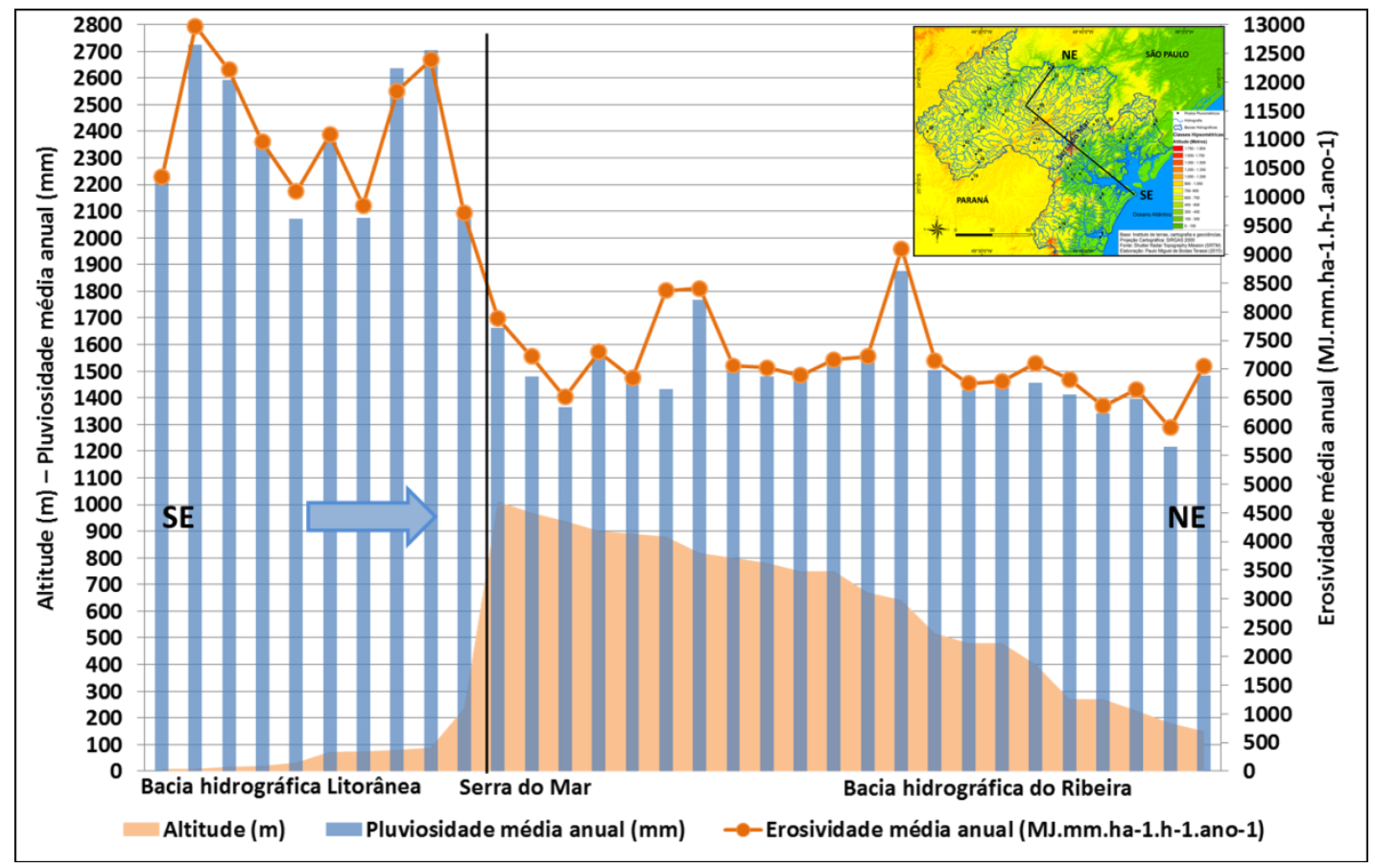

Figura 5 - Perfil esquemático da altitude (metros) dos postos pluviométricos da área em estudo, da pluviosidade média anual $(\mathrm{mm})$ e da erosividade média anual (MJ.mm.ha ${ }^{1} \cdot \mathrm{h}^{-}$ 1. ano ${ }^{-1}$ ). 
Observa-se uma concentração da pluviosidade para os meses de primavera e verão, de outubro a março, com $61,9 \%$ e $66,7 \%$ dos totais de pluviosidade anual ocorrente nestas duas estações para, respectivamente, as bacias hidrográficas do Ribeira e Litorânea. Mesmo com maiores médias de pluviosidade ao longo do ano, a bacia Litorânea apresenta a maior redução de pluviometria para os meses de outono e inverno em comparação à bacia do Ribeira, o que se atribui a diminuição do papel desempenhado pelo efeito da maritimidade para a ocorrência da elevada pluviometria mais atuante no período de dezembro a fevereiro, como destacam Fritzsons et al. (2011) e Silva et al. (2015) (Figura 6).

Os resultados demostraram que os totais médios mensais os postos pluviométricos situados na bacia hidrográfica Litorânea apresentaram maiores totais em relação àqueles situados na bacia hidrográfica do Ribeira. As maiores diferenças foram verificadas nos meses de janeiro, fevereiro e março, período no qual se verificou em média $954,8 \mathrm{~mm}$ para a bacia Litorânea, ao passo que os postos pluviométricos inseridos na bacia do Ribeira resultaram uma média $507,8 \mathrm{~mm}$ (Figura 6). Explica-se que os valores de pluviometria para a bacia Litorânea são mais elevados devido à influência da maritimidade conjugada à atuação mais direta e incisiva da massa Tropical atlântica na formação das chuvas (VANHONI; MENDONÇA, 2008), enquanto que a orografia da Serra do Mar funciona como uma barreira para que este mesmo mecanismo atmosférico influencie na ocorrência de chuvas na bacia hidrográfica do Ribeira.

Os meses de junho, julho e agosto mostraram as menores diferenças pluviométricas entre as duas bacias hidrográficas em estudo, tendo sido verificado uma média de 329, $8 \mathrm{~mm}$ e 262,0 mm, respectivamente, para a bacia Litorânea e do Ribeira (Figura 6). Essa proximidade nos valores de pluviosidade para o trimestre citado acima se dá justamente porque os mecanismos atmosféricos responsáveis pela geração das chuvas nesse período são apresentam maior abrangência e estão diretamente relacionados à maior atuação da frente polar atlântica (ZANDONADI et al., 2015).

As estimativas de erosividade mostraram que a área de estudo apresenta uma concentração do potencial erosivo para o período que vai de setembro a março, período que as duas bacias hidrográficas apresentaram valores de erosividade média superior a $500 \mathrm{MJ} \cdot \mathrm{mm} \cdot \mathrm{ha}^{-1} \cdot \mathrm{h}^{-1} \cdot \mathrm{mês}^{-1}$, e que concentra $83,2 \%$ e $76,5 \%$ do total anual de erosividade para, nessa ordem, a bacia hidrográfica Litorânea e do Ribeira. De outra forma, o período que vai de maio a agosto corresponde àquele de menor erosividade de chuvas, com valores inferiores a $500 \mathrm{MJ} \cdot \mathrm{mm} \cdot \mathrm{ha}^{-1} \cdot \mathrm{h}^{-1} \cdot \mathrm{mês}^{-1}$ (Figura 7).

O aumento da precipitação para a bacia Litorânea para o trimestre de janeiro a março resulta em um potencial erosivo médio superior a 1.500 MJ.mm.ha-1.h $\mathrm{h}^{-1} \cdot \mathrm{mês}^{-1}$, período com uma concentração de $52,7 \%$ do potencial erosivo anual, com destaque para o mês de janeiro, com erosividade média de 2.447,4 MJ.mm.ha-1 $\cdot \mathrm{h}^{-1} \cdot \mathrm{mês}^{-1}$. Por sua vez, a bacia hidrográfica do Ribeira apresenta uma menor concentração no primeiro trimestre, com 40,9\% do total anual de erosividade das chuvas (Figura 7), condição que está associada à menor influência da maritimidade e da massa Tropical atlântica devido ao impedimento da barreira da Serra do Mar. 


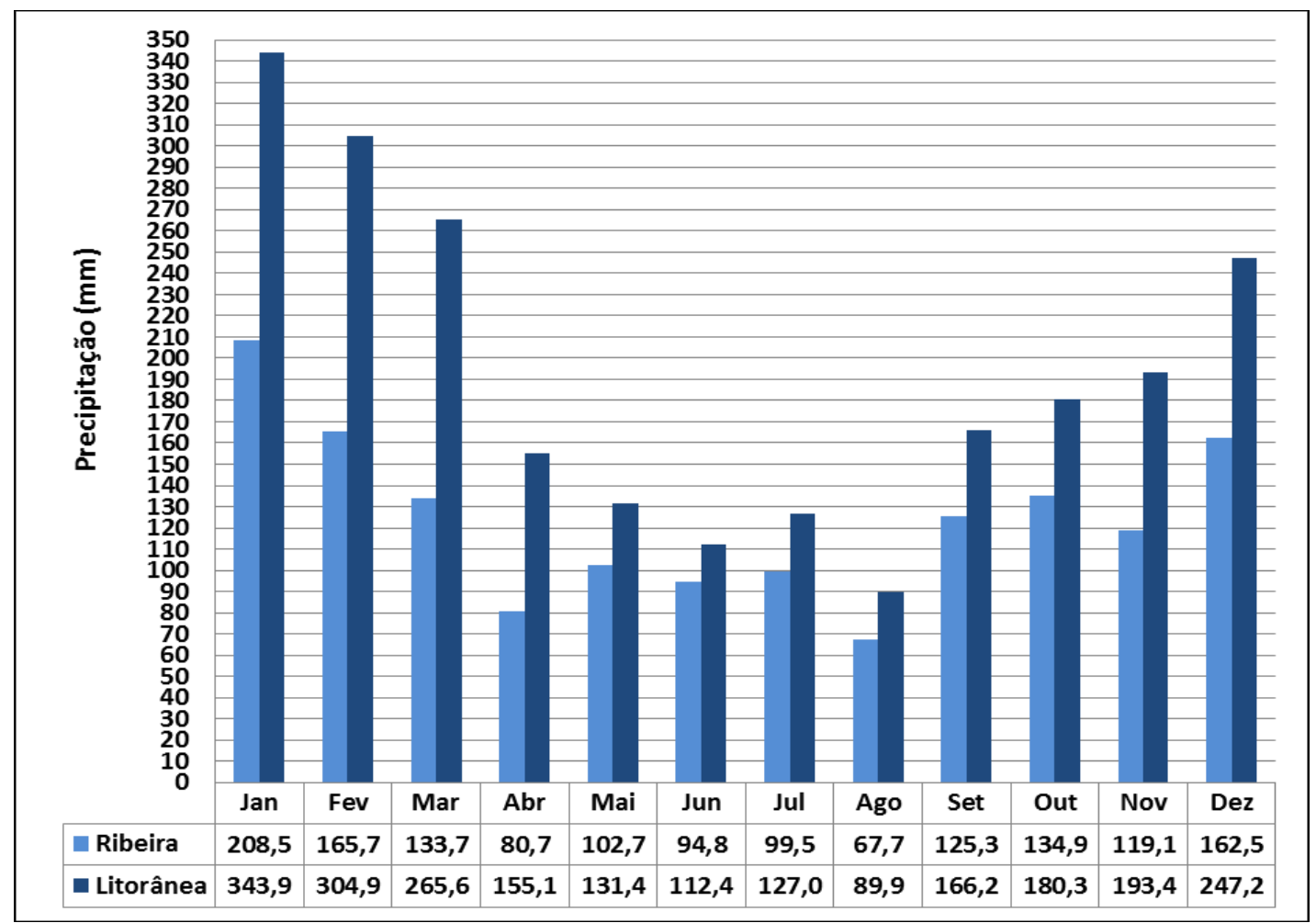

Figura 6 - Distribuição média mensal da precipitação pluviométrica $(\mathrm{mm})$ para as bacias hidrográficas do rio Ribeira e Litorânea - Paraná.

Com a dependência dos mecanismos atmosféricos extratropicais para a geração das chuvas, com destaque para frente Polar atlântica, os valores de erosividade são mais homogêneos entre as duas bacias hidrográficas durante o período que vai de maio a agosto. Destaca-se que de maio a agosto os valores entre as áreas de estudo são semelhantes e que, inclusive, a equação determina um potencial erosivo maior para a bacia do Ribeira, igual a $1.420,8 \mathrm{MJ} . \mathrm{mm}$.ha${ }^{1}$. $\mathrm{h}^{-1}$. $\mathrm{mês}^{-1}$, enquanto que a bacia Litorânea obteve $1.323,7 \mathrm{MJ} . \mathrm{mm}$. ha ${ }^{-1} \cdot \mathrm{h}^{-1}$. mês 1 para a média deste período (Figura 7). Mesmo com valores de pluviometria mais elevada para este período, a bacia Litorânea apresentou uma menor erosividade, pois a equação utilizada considera a proporção de pluviosidade ocorrente no mês em relação à média anual, o coeficiente de relação de chuva (Figuras 7 e 9 ).

A distribuição mensal da erosividade das chuvas para o recorte de estudo está em conformidade aos resultados obtidos por Waltrick et al. (2015), com uma tendência de concentração da erosividade das chuvas no período que vai de setembro a março, igualmente concordante com os resultados de Silva (2004) e Trindade et al. (2016) para o território brasileiro. 


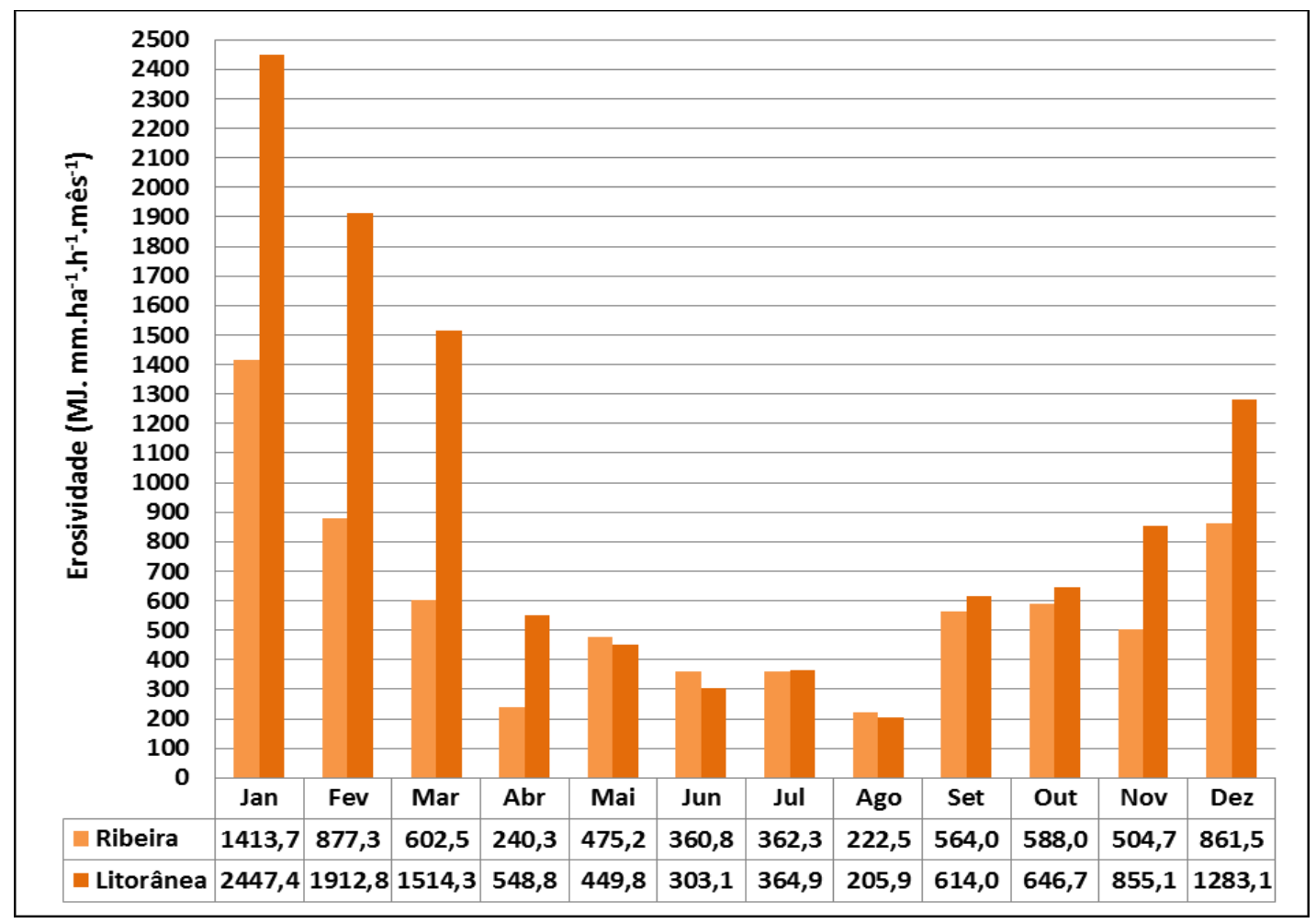

Figura 7 - Distribuição média mensal da erosividade (MJ.mm.ha-1. $\mathrm{h}^{-1} \cdot \mathrm{mês}^{-1}$ ) para as bacias hidrográficas do rio Ribeira e Litorânea - Paraná.

Durante o verão o aquecimento da superfície e o aumento de umidade no continente tendem a instabilizar a atmosfera e propiciar a formação de maiores totais de pluviosidade (GRIMM, 2009). A atuação conjungada de sistemas atmosféricos extratropicais e intertropicais responde pelos elevados totais de pluviosidade para o Brasil Meridional, conforme Baldo (2006), Silva et al. (2006) e Zandonadi et al. (2015).

Seluchi e Chou (2009) e Reboita et al. (2010) destacam a participação das ZCAS (Zona de Convergência do Atlântico Sul) para a ocorrência da estação chuvosa nesta região, dada a elevada interação dos sistemas frontais com a convecção tropical. Mello et al. (2017) analisaram as condições atmosféricas para a geração de chuvas extremas no município de Paranaguá, localizado na bacia Litorânea, e indicaram que, majoritariamente, os eventos de pluviosidade mais intensa estiveram relacionados a configuração da Zona de Convergência de Umidade (ZCOU), embora a massa Tropical atlântica e o sistema frontal atlântico tenha gerado outros totais de chuva de significativo total acumulado.

O mês de janeiro, o mais chuvoso e de maior erosividade para a área de estudo, apresenta pluviosidade média entre 304 a $412 \mathrm{~mm}$ e erosividade média entre 1.977 a 2.942,6 MJ.mm.ha-1.h-1 .mês $^{-1}$ para a bacia hidrográfica Litorânea, enquanto que a bacia hidrográfica do Ribeira tem médias entre 179,1 a 287,9 $\mathrm{mm}$ de pluviosidade e 1.151,9 a 2.170,9 MJ.mm.ha-1. $\mathrm{h}^{-1} \cdot \mathrm{mês}^{-1}$ (Figura 8). Esses resultados indicam que durante o mês de janeiro, com a maior atuação da massa Tropical Atlântica e o aquecimento das águas do Oceano Atlântico e, consequentemente, o efeito da maritimidade, a bacia hidrográfica Litorânea 
registra médias de pluviosidade comparadas as mais elevadas registradas para o Brasil (KELLER FILHO et al., 2005) e, desta forma, aos maiores potenciais de erosividade do território brasileiro (SILVA, 2004). Por sua vez, os resultados demonstrados para o mês de janeiro para a bacia hidrográfica do Ribeira demonstra o papel desempenhado pela barreira orográfica da Serra do Mar devido aos menores totais pluviométricos e a redução significativa do potencial erosivo das chuvas em relação à bacia Litorânea.

Segundo Baldo (2006), Silva et al. (2006) e Zandonadi et al. (2015), os mecanismos que atuam na formação das chuvas estão mais restritos à atuação dos sistemas atmosféricos extratropicais no período de inverno. Ainda, Grimm (2009) destaca que o menor valor observado no mês de agosto se dá pelo deslocamento do Jato Subtropical das latitudes paranaenses para o Rio Grande do Sul, justamente o mês com os menores totais médios de pluviosidade e erosividade para a maior parte do estado do Paraná (NERY, 2006; FRITZSONS et al., 2011; WALTRICK et al. 2015) e, conforme Keller, Assad e Lima (2005) e Trindade et al. (2016) para o território brasileiro, dada às características do clima Tropical.

Observa-se para o mês de agosto uma pluviosidade média entre 50,4 a $79,7 \mathrm{~mm}$ e a 72,1 a $105 \mathrm{~mm}$ para, respectivamente, as bacias hidrográficas do Ribeira e Litorânea. Estes menores valores de erosividade respondem por valores médios entre 155,6 a $275,5 \mathrm{MJ} \cdot \mathrm{mm} \cdot \mathrm{ha}^{-1} \cdot \mathrm{h}^{-1} \cdot \mathrm{mês}^{-1}$ para a bacia do Ribeira e 134,3 a $274 \mathrm{MJ} \cdot \mathrm{mm} \cdot \mathrm{ha}^{-1} \cdot \mathrm{h}^{-1} \cdot \mathrm{mês}^{-1}$ para a bacia Litorânea (Figura 9). Em relação ao mês de janeiro, nota-se que os intervalos de pluviosidade e erosividade entre as duas áreas são menores, dado que os mecanismos de predominantes na geração de chuvas, os sistemas frontais, atuam de forma mais homogênea em relação ao verificado para o mês de janeiro (CARDOZO; REBOITA; GARCIA, 2015; ZANDONADI et al., 2015).

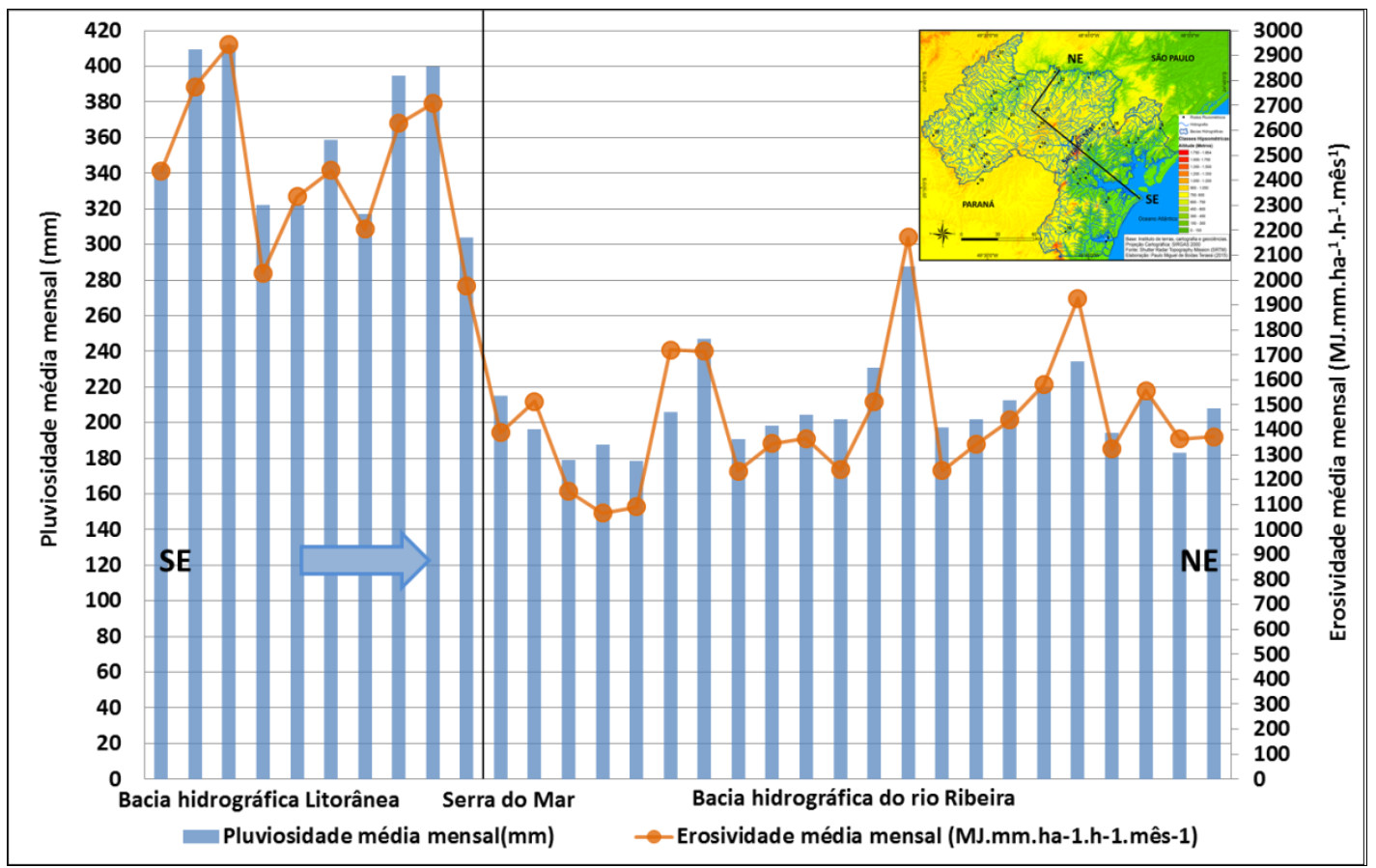

Figura 8 - Perfil esquemático da distribuição da pluviosidade média $(\mathrm{mm})$ e da erosividade média (MJ.mm.ha ${ }^{1} \cdot \mathrm{h}^{-1} \cdot \mathrm{mês}^{-1}$ ) para o mês de janeiro na área de estudo. 


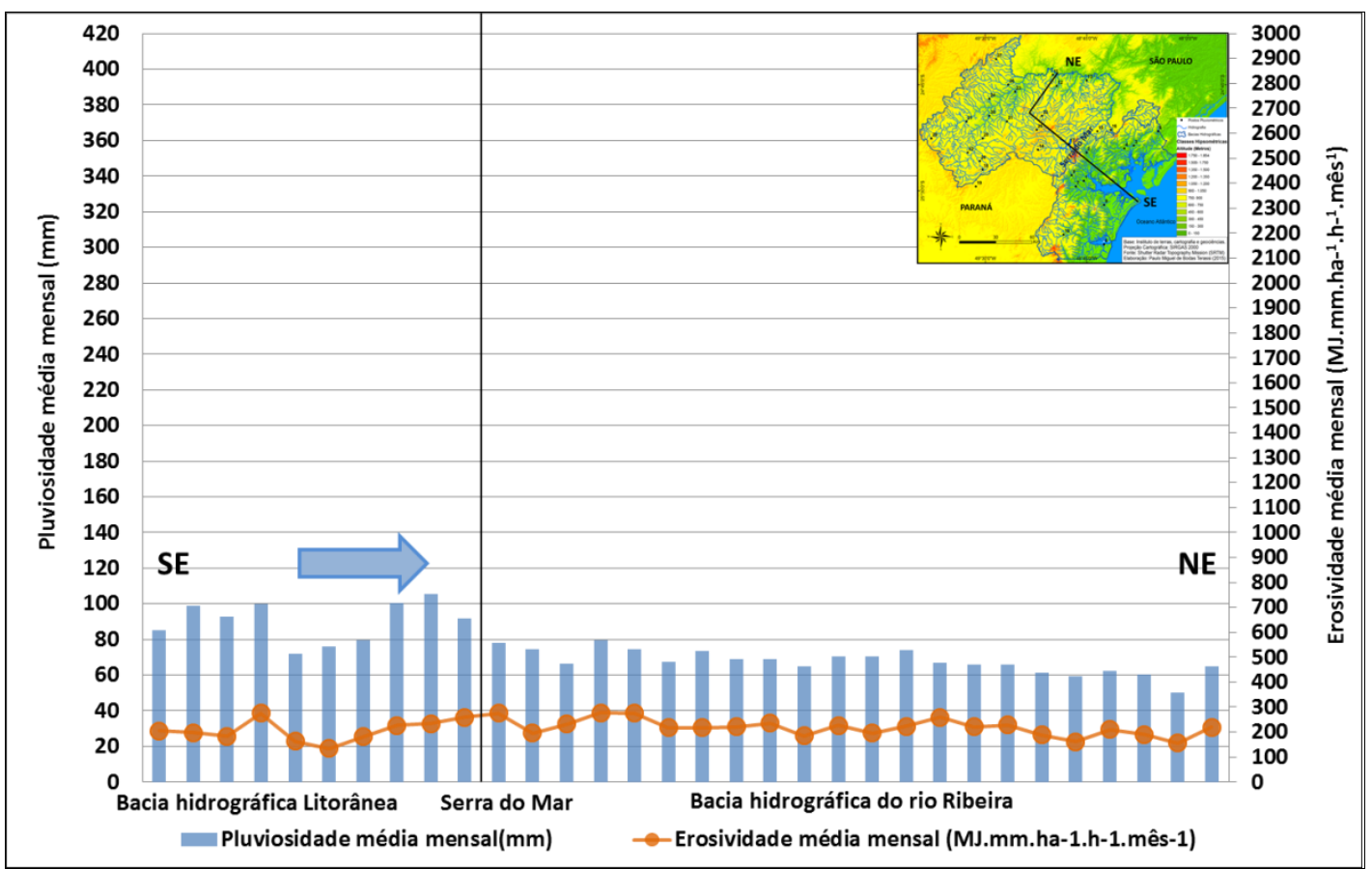

Figura 9 - Perfil esquemático da distribuição da pluviosidade média $(\mathrm{mm})$ e da erosividade média (MJ.mm.ha ${ }^{1} \cdot \mathrm{h}^{-1} \cdot \mathrm{mês}^{-1}$ ) para o mês de agosto na área de estudo.

\section{CONSIDERAÇÕES FINAIS}

Os resultados indicaram que a bacia hidrográfica Litorânea caracteriza-se pelas maiores médias de pluviosidade e erosividade das chuvas, sendo esta última com uma média anual de $11.146 \mathrm{MJ} \cdot \mathrm{mm} \cdot \mathrm{ha}^{1} \cdot \mathrm{h}^{-1} \cdot \mathrm{mês}^{-1}$ e $58,6 \%$ superior à bacia hidrográfica do Ribeira, o que se atribui a atuação mais direta da maritimidade, da massa Tropical atlântica, sobretudo no verão, e ao efeito orográfico da Serra do Mar. Por sua vez, a bacia hidrográfica do Ribeira representa uma região de sombra das chuvas, dado o papel desempenhado pela barreira orográfica da Serra do Mar, e apresenta valores de pluviosidade aproximadamente 37,3\% inferior à bacia Litorânea e, consequentemente, com erosividade média de $7.027,7 \mathrm{MJ} \cdot \mathrm{mm} \cdot \mathrm{ha}^{1} \cdot \mathrm{h}^{-1} \cdot \mathrm{mês}^{-1}$.

Destaca-se que os setores de maiores diferenças de relevo e próximos a costa litorânea mostraram as maiores variações dos totais de pluviosidade e erosividade das chuvas, ao passo que nas porções de relevo mais plano e continente adentro a distribuição da pluviosidade e do potencial erosivo são mais homogêneas.

O mês de janeiro, o mais chuvoso para a área de estudo, apresenta as maiores diferenças de pluviosidade entre as duas áreas de estudo, posto o papel desempenhado pela orografia da Serra do Mar à maior atuação da massa Tropical Atlântica e pelo efeito da maritimidade. No mês de agosto, o mais seco, com a predominância de sistemas atmosféricos extratropicais, as bacias hidrográficas apresentaram menores diferenças entre os resultados de pluviosidade e erosividade média, uma vez que estes mecanismos atuam de forma mais homogênea para a geração de chuvas. 


\section{AGRADECIMENTOS}

O presente trabalho foi realizado com apoio do Programa Nacional de Cooperação Acadêmica da Coordenação de Aperfeiçoamento de Pessoal de Nível Superior - Edital CAPES 071/2013 - Processo número 88881.068465/2014-01. Os autores agradecem a Coordenação de Aperfeiçoamento de Pessoal de Nível Superior pela concessão da Bolsa de Doutorado ao primeiro autor e o Conselho Nacional de Desenvolvimento Científico e Tecnológico à Bolsa de Produtividade em Pesquisa (Nível 1D) concedida ao segundo autor (303676/2013-2).

\section{REFERÊNCIAS}

ÁlVARES, C. A.; STAPE, J. L.; SENTELHAS, P. C.; DE MORAES GONÇALVES, J.L.; SPAROVEK, G. Köppen's climate classification map for Brazil. Meteorologische Zeitschrift, Berlin, v.22, n.6, p.711-728, 2013.

ANDRADE, A. R.; NERY, J. T. Análise da precipitação pluviométrica diária, mensal e interanual da bacia hidrográfica do Rio Ivaí, Brasil. Investigaciones Geográficas. Cidade do México, v.52, n.1, p.7-30, 2003.

APARECIDO, L. E. O; ROLIM, G. S.; RICHETTI, J.; SOUZA, P. S.; JOHANN, J. A. Köppen, Thornthwaite and Camargo climate classifications for climatic zoning in the State of Paraná, Brazil. Ciência e Agrotecnologia (Online), Lavras, v.40, n.4, p. 405-417, 2016.

ARAI, F. K. ; GONÇALVES, G. G. G.; PEREIRA, S. B.; COMUNELLO, E. ; VITORINO, A. C. T.; DANIEL, O. Espacialização da precipitação e erosividade na bacia hidrográfica do Rio Dourados - MS. Engenharia Agrícola, Jaboticabal, v. 30, n.5, p.922-931, 2010.

BALDO, M.C. Variabilidade Pluviométrica e a Dinâmica Atmosférica da Bacia do Rio Ivaí. 2006. 153 f. Tese (Doutorado). Programa de Pós-Graduação em Geografia. Universidade Estadual Paulista "Júlio de Mesquita Filho", Presidente Prudente, 2006.

BERTONI, J.C.; TUCCI, C.E.M. Precipitação. In: TUCCI, C. E. M. (Org.) Hidrologia: Ciência e Aplicação. 2a Edição. Porto Alegre: Editora da Universidade Federal do Rio Grande do Sul/Associação Brasileira de Recursos Hídricos, p. 727-768, 1997.

BRITO, T. T.; OLIVEIRA JÚNIOR, J. F. de; LYRA, G. B.; GOIS, G.; ZERI, M. Multivariate analysis applied to monthly rainfall over Rio de Janeiro state, Brazil. Meteorology and Atmospheric Physics, Berlin, v. 128, n.5, p. 1-10, 2016.

CÂNDIDO, D. H.; NUNES, L. H. Influência da orografia na precipitação da área entre o vale do rio Tietê e a Serra da Mantiqueira. Geousp, São Paulo, v.1, n. 24, 2008.

CARDOZO, A. B.; REBOITA, M. S.; GARCIA, S. R. Climatologia de Frentes Frias na América do Sul e sua relação com o Modo Anular Sul. Revista Brasileira de Climatologia, Curitiba, v.17, n.1, p. 9-29, 2015. 
CARVALHO, J.R.P.; ASSAD, E.D. Análise espacial da precipitação pluviométrica no estado de São Paulo: comparação de métodos de interpolação. Engenharia Agrícola, Jaboticabal, v.25, n.2, p.377-384, 2005.

CARVALHO, R. G. As bacias hidrográficas enquanto unidades de planejamento e zoneamento ambiental no Brasil. Caderno Prudentino de Geografia, Presidente Prudente, v. Especial, n.36, p. 26-43, 2014.

CAVIGLIONE, J. H.; KIIHL, L. R. B.; CARAMORI, P. H.; OLIVEIRA, D. Cartas climáticas do Paraná. Londrina: IAPAR, 2000. CD ROM.

CHIERICE, R.A.F.; LANDIM, P.M.B. Variabilidade espacial e temporal de precipitação pluviométrica na bacia hidrográfica do rio Mogi Guaçu. Geociências, São Paulo, v.33, n.1, p.157-171, 2014.

CORREA, M.G.G. Distribuição espacial e variabilidade da precipitação pluviométrica na bacia do rio Piquiri - PR. 2013.102f. Dissertação (Mestrado). Programa de Pós-Graduação em Geografia Física, Universidade de São Paulo, São Paulo, 2013.

CORREA, M.G.G.; GALVANI, E. Évaluation de l'effet orographique dans le bassin versant du Piquiri - Paraná/Brésil. In: XXIX Colloque de I'Association Internationale de Climatologie, Lausanne (Besançon), Associação Internacional de Climatologia, p.211-216, 2016.

FONTÃO, P. A.B; ZAVATTINI, J.A. Regionalização das chuvas anuais na bacia do Pardo, Brasil. Caderno Prudentino de Geografia, Presidente Prudente, Volume especial, n.36, p.143-158, 2014.

FRITZSONS, E.; MANTOVANI, L. E.; WREGE, M. S.; CHAVES NETO, A. Análise da pluviometria para definição de zonas homogêneas no estado do Paraná. RA'E GA: o Espaço Geográfico em Análise, Curitiba, v.23, n.1, p.555-572, 2011.

GRIMM, A. M. Clima na Região Sul. In: CAVALCANTI, I. F. A.; FERREIRA, N. J.; JUSTI DA SILVA, M.G.A.; SILVA DIAS, M. A. F. Tempo e Clima no Brasil. $1^{a}$ Edição. São Paulo, Oficina de Textos, p. 259-275, 2009.

HOYOS, N.; WAYLEN P.; JARAMILLO A. Seazonal and spatial patterns of erosivity in a tropical watershed of the Colombian. Journal of Hidrology, Amsterdam, v.314, n.1-4, p.177-191, 2005.

ITCG (Instituto de Terras, Cartografia e Geodésia). Produtos Cartográficos. Disponível em: <http://www.itcg.pr.gov.br/modules/conteudo/conteudo. php?c

onteudo=47. Acesso em 14 de janeiro de 2015.

KOGA-VICENTE, A.; NUNES, L. H. Impactos socioambientais associados à precipitação em municípios do litoral paulista. Geografia, Rio Claro, v.36, n.3, p. 571-588, 2011.

KÖPPEN, W. Climatologia: con un estudio de los climas de la tierra. Fondo de Cultura Econômica. México. 1948. 479p.

KELLER FILHO, T; ASSAD, E.D.; LIMA, P.R.S.R. Regiões pluviometricamente homogêneas no Brasil. Revista Brasileira de Pesquisa Agropecuária, Brasília, v.40, n.4, p.311-322, 2005. 
LUZ, R.; RODRIGUES, C.; Anthropogenic changes urbanised hidromorphological systems in a humid tropical environment River Pinheiros, São Paulo, Brasil. Zeitschrift fur Geomorphologie, Stuttgart, v.59, n.2, p.109-135, 2015.

MA, X.;YANDONG, H.; XU, J.; VAN NOORDWIJK,M; LU,X. Spatial and temporal variation in rainfall erosivity in a Himalayan watershed. Catena, Amsterdam, v. 121, p.248-259, 2012.

MAACK, R. Geografia Física do Estado do Paraná. 4a Edição. Ponta Grossa: Editora UEPG. 2012. 526p.

MELLO, Y.R.; LOPES, F.C.A.; ROSEGHINI, W.F.F. Características climáticas e análise rítmica aplicada a episódios extremos de precipitação e temperatura no município de Paranaguá, PR. Revista Brasileira de Climatologia, Curitiba, v.20, n.1, p.313-336, 2017.

MILANESI, M.A.; GALVANI, E. Efeito orográfico na Ilha de São Sebastião (Ilha Bela - SP). Revista Brasileira de Climatologia, Curitiba, v.9, n.2, p.68-79, 2011.

MONTEBELLER, C.A.; CEDDIA, CARVALHO, D.F.; VIEIRA, S.R.; FRANCO, E.M. Variabilidade espacial do potencial erosivo das chuvas no Estado do Rio de Janeiro. Engenharia Agrícola, Jaboticabal, v.27, n.2, p.426-435, 2007.

NERY, J. T.; MARTINS, M. L. F.; SANTANNA NETO, J. L. Variabilidade da Precipitação no Brasil Meridional. Acta Scientiarum Technology (UEM), Maringá, v.24, n.6, p.1687-1695, 2002.

NERY, J. T. Dinâmica climática da região Sul do Brasil. Revista Brasileira de Climatologia, Curitiba, v.1, n.1, p. 61-75, 2006.

NIMER. E. Climatologia do Brasil. 2a Edição. Rio de Janeiro: Instituto Brasileiro de Geografia e Estatística, 1989. 421p.

OLIVEIRA, L.F.C.; FIOREZE, A.P.; MEDEIROS, A.M.M.; SILVA, M.A.S. Comparação de metodologias de preenchimento de falhas em séries históricas de precipitação pluvial anual. Revista Brasileira de Engenharia Agrícola e Ambiental, Campina Grande, v.14, n.11, p.1186-1192, 2010.

OLIVEIRA, P.T.S.; RODRIGUES, D. B. B.; ALVES SOBRINHO, T.; CARVALHO, D. F.; PANACHUKI, E. Spatial variability of the rainfall erosive potential in the State of Mato Grosso do Sul, Brazil. Engenharia Agrícola, Jaboticabal, v.32, n.1, p.6979, 2012.

OLIVEIRA, P.T.S.; WENDLAND, E.; NEARING, M.A. Rainfall erosivity in Brazil: a review. Catena, Amsterdam, v.100, n.1, p.139-147, 2012.

PANAGOS, P.; BORELLI, P.; MEUSBURGER, K.; YU, B.; KLIK, A.; JAE LIM, K.; YANG, J.E.; NI, J.; MIAO, C.; CHATTOPADHYAY, N.; SADEGHI, S.H.; HAZBAVI, Z.; ZABIHI, M.; LARIONOV, G.A.; KRASNOV, S.F.; GOROBETS, A.V.; LEVI, Y.; ERPUL, G.; BIRKEL, C.; HOYOS, N.; NAIPAL, V.; OLIVEIRA, P.T.S.; BONILLA, C.A.; MEDDI, M.; NEL, W.; AL DASHTI, H.; BONI, M.; DIODATO, N.; VAN OOST, K.; NEARING, M.; BALLABIO, C. Global rainfall erosivity assessment based on high-temporal resolution rainfall records. Nature, Londres, v.7, n.4175, p.1-12, 2017.

PELLEGATTI, C. H. G.; GALVANI, E. Avaliação da precipitação na Serra do Mar SP eventos de diferentes intensidade e duração. Geousp, São Paulo, v.13, n.27, p.132-148, 2010. 
PORTO, M.F.A.; PORTO, R.L.L. Gestão de bacias hidrográficas. Estudos Avançados, São Paulo, v.22, n.63, p.43-60, 2008.

REBOITA, M.S.; GAN, M.A.; ROCHA, R.P.; AMBRIZZI, T. Regimes de precipitação na América do Sul. Revista Brasileira de Meteorologia, São Paulo, v.25, n.2, p.185-204, 2010.

RIBEIRO, A. G. Caracterização termo pluviométrica da bacia hidrográfica do rio Pirapó - PR. Boletim de Geografia. Maringá, v.5, n.1, p.91-135, 1987.

RODRIGUES, C. Avaliação do impacto humano da urbanização em sistemas hidrogeomorfológicos. Desenvolvimento e aplicação de metodologia na Grande São Paulo. Revista do Departamento de Geografia (USP), São Paulo, v.20, p.111-125, 2010.

RUFINO, R. L.; BISCAIA, R. C. M.; MERTEN, G. H. Determinação do potencial erosivo da chuva do estado do Paraná, através de pluviometria: terceira aproximação. Revista Brasileira de Ciência do Solo, Campinas, v.17, n.1, p. 439$444,1993$.

SANT'ANNA NETO, J. L. Dinâmica Atmosférica e o caráter transicional do clima na Zona Costeira Paulista. Revista do Departamento de Geografia (USP), São Paulo, v.8, n.1, p.35-49, 1994.

SANT'ANNA NETO, J. L. A erosividade das chuvas no estado de São Paulo. Revista do Departamento de Geografia (USP), São Paulo, v.9, n.1, p.35-49, 1995.

SELUCHI, M.E.; CHOU, S.C. Synoptic patterns associated with landslides events in the Serra do Mar, Brazil. Theoretical and Applied Climatology, Berlim, v.98, n.1, p.67-77, 2009.

SILVA, A.M. Rainfall erosivity map for Brazil. Catena, Amsterdam, v.57, n.3, p.251-259. 2004.

SILVA, C. B.; SANT'ANNA NETO, J. L.; TOMMASELLI, J. T. G.; PASSOS, M. M. Dinâmica atmosférica e análise geoestatística do clima na área de integração paisagística 'Raia Divisória' SP/PR/MS: uma proposta de tipologia climática. Revista Brasileira de Climatologia, Curitiba, v.2, n.1, p.53-70, 2006.

SILVA, A.M.; SILVA, M.L.N.; CURI, N.; AVANZI, J.C.; FERREIRA, M.M. Erosividade da chuva e erodibilidade de Cambissolo e Latossolo na região de Lavras, Sul de Minas Gerais. Revista Brasileira de Ciência do Solo, Viçosa, v.33, n.6, p.1811-1820, 2009.

SILVA, M.A.; SILVA, M.L.N.; CURI, N.; SANTOS, G.R.; MARQUES, J.J.G.S.M.; MENEZES, M.D.; LEITE, F.P. Avaliação e espacialização da erosividade da chuva no Vale do rio Doce, região Centro-Leste do Estado de Minas Gerais. Revista Brasileira de Ciência do Solo, Viçosa, v.34, n.4, p.1029-1039, 2010.

SILVA, A. M. A.; OLIVEIRA, A.G.; LOEZER, T.L.; SOUZA, R.M. Avaliação do comportamento da precipitação entre o Primeiro Planalto Paranaense e o Litoral do Paraná no ano hidrológico 2010/2011. Revista Geonorte, Edição Especial 2, v.2, n.5, p.967-974, 2012.

SILVA, W.L.; DERECZYNSKI, C.; CHANG, M.; FREITAS, M.; MACHADO, B.J.; TRISTÃO, L.; RUGGERI, J. Tendências observadas em indicadores de extremos 
climáticos de temperatura e precipitação no Estado do Paraná. Revista Brasileira de Meteorologia, São Paulo, v.30, n.2, p.181-194, 2015.

SOUZA, V.; GASPARETTO, N. V. L. Aplicação da equação universal de perdas de solo (EUPS) na bacia do córrego Pinhalzinho Segundo, noroeste do Paraná. Revista Brasileira de Geomorfologia, Uberlândia, v.13, n.3, p. 267-278, 2012.

TONETTI, E. L.; NUCCI, J. C.; SOUZA, F. X. S.; VALASKI, S. Alagamentos frequentes na área urbana de Paranaguá - PR. Geografia, Londrina, v.22, n.2, p.43-56, 2013.

TRINDADE, A.L.F.; OLIVEIRA, P.T.S.; ANACHE, J.A.A.; WENDLAND, E. Variabilidade espacial das chuvas no Brasil. Revista de Pesquisa Agropecuária, Brasília, v.51, n.12, p.1918-1928, 2016.

VANHONI, F.; MENDONCA, F. A. O clima no litoral do Estado do Paraná. Revista Brasileira de Climatologia, Curitiba, v.3, n.1, p.49-64, 2008.

VILLELA, S. M.; MATTOS, A. Hidrologia aplicada. São Paulo: McGraw-Hill do Brasil, 1975. 245p.

WALTRICK, P. C.; MACHADO, M. A. M.; DIECKOW, J.; OLIVEIRA, D. Estimativas da erosividade de chuvas no estado do Paraná pelo método da pluviometria: Atualização com dados de 1986 a 2008. Revista Brasileira de Ciência do Solo, Viçosa, v.39, n.1, p.256-267, 2015.

ZANDONADI, L.; ACQUAOTTA, F.; FRATIANNI, S.; ZAVATTINI, J. A. Changes in precipitation extremes in Brazil (Paraná River Basin). Theoretical and Applied Climatology, Berlim, v.119, n.1, p.1-18, 2015.

ZHANG, G.H.; NEARING, M.A.; LIU, B.Y. Potencial effects of climate change on rainfall erosivity in the Yellow river basin of China. Transactions of the American Society of Agriculture Engineers, Washington, v.48, n.2, p.511-517, 2005. 